\title{
School Matters: The Effects of School Experiences on Youth's Attitudes toward Immigrants
}

\author{
Katharina Eckstein $\mathbb{D}^{1} \cdot$ Marta Miklikowska $^{2} \cdot$ Peter Noack $^{1}$
}

Received: 22 April 2021 / Accepted: 1 September 2021 / Published online: 24 September 2021

(c) The Author(s) 2021, corrected publication 2022

\begin{abstract}
Although schools have been described as an important socialization context for the development of intergroup attitudes, longitudinal multilevel studies are still rare within this field. This 3-wave study (with annual assessments) of German adolescents $\left(N=1292 ; M_{\text {age }}=13.86 ; 51.8 \%\right.$ female $)$ examined the role of school experiences (perceived multicultural education, supportive peer relations in class, democratic classroom climate) in the development of youth's negative attitudes toward immigrants. Longitudinal multilevel analyses revealed that a democratic classroom climate predicted youth's attitudes at the individual level. At the classroom level class-average perceptions of a democratic classroom climate, supportive peer relations in class, and multicultural education (the latter solely among male, higher track students) were associated with less negative attitudes toward immigrants. In addition, age moderated the effect of school experiences on attitudes, showing that perceptions of a democratic climate at the classroom level mattered in particular among older adolescents. The findings suggest that school experiences are related to youth's negative attitudes toward immigrants and can therefore help to reduce the risk of prejudice development.
\end{abstract}

Keywords Prejudice $\cdot$ Attitudes toward immigrants $\cdot$ School $\cdot$ Classroom climate $\cdot$ Youth

\section{Introduction}

As societies become increasingly culturally diverse, reports of intolerant attitudes toward immigrants are viewed with concern-a concern that becomes all the more serious when it affects young people. Youth is considered a formative period in life for the development of social and political attitudes (Neundorf \& Smets, 2017). Accordingly, besides becoming more aware of one's own social identities, intergroup attitudes, which reflect relatively enduring and general evaluations of various social groups (APA, n.d.), stabilize (Crocetti et al., 2021). With an increasing

Supplementary information The online version contains supplementary material available at https://doi.org/10.1007/s10964021-01497-x.

Katharina Eckstein

katharina.eckstein@uni-jena.de

1 Department of Educational Psychology, Friedrich Schiller University of Jena, Humboldtstr. 27, 07743 Jena, Germany

2 Department of Sociology, Beteendevetarhuset, Umeå University, Mediagränd 14, 90187 Umeå, Sweden political awareness, yet still searching for a sense of identity, young people are particularly susceptible to contextual influences (impressionable years hypothesis; e.g., Sears \& Levy, 2003).

Of the many factors that shape young people's intergroup attitudes, experiences in school deserve particular attention as young people spend much time in educational settings and schools share the common goal of educating students to become informed citizens (Neundorf \& Smets, 2017) and to counteract prejudice (Hess, 2009). Moreover, socialization and social learning perspectives (e.g., Bandura, 1977) see schools as miniature societies that bring together young people with various backgrounds and therefore allow learning about social interaction and group processes (Dessel, 2010). Accordingly, studies have shown that school experiences are linked to youth's intergroup attitudes (Barber et al., 2013). However, the school context offers a variety of influences. Apart from structural characteristics (e.g., cultural diversity), formal learning experiences (e.g., curricular initiatives in multicultural education) can be distinguished from informal learning experiences (e.g., prevailing school or classroom climate; Scheerens, 2011). Since these experiences can be furthermore located at different levels of the school context, ranging from an 
individual student in a particular classroom or proximate dynamics within class to more distal processes at the school level, an ecological view of school has been proposed (Eccles \& Roeser, 2009). Yet, longitudinal studies accounting for the hierarchical nature of the school context are still rare, as are considerations of age-specific trends that would allow examining whether young people are particularly responsive to school influences at a certain age and thus at a certain stage of development. Drawing on longitudinal multilevel data, it was therefore the goal of the present study to examine the effects of formal-curricular and climatic school experiences on German youth's negative attitudes toward immigrants, while also accounting for potential age-related patterns.

\section{Curricular School Experiences and Youth's Intergroup Attitudes}

Curricular characteristics reflect an important formal aspect of the school context and one approach that has attracted particular research attention in this regard is multicultural education (Banks \& Banks, 2004). The concept subsumes a variety of educational practices ranging from temporary school-based interventions to general approaches to teaching that can be implemented with or without intergroup contact (Aboud \& Levy, 2000). More precisely, multicultural education "aims to provide students with knowledge and attitudes necessary to understand, respect, and interact harmoniously as equals with members of different ethnic groups" (Aboud \& Levy, 2000, p. 277). It can promote norms of tolerance, thereby helping young people to look beyond group boundaries, to identify similarities between various groups, or to value cultural diversity (Thijs \& Verkuyten, 2014) and should therefore be negatively related to prejudice.

Indeed, research showed that multicultural education is associated with more positive out-group evaluations among minority and majority youth (van Bommel et al., 2020). Previous findings further indicate that multicultural education is more frequently applied in culturally diverse schools compared to culturally homogeneous settings (Thijs \& Verkuyten, 2014). Culturally diverse schools do not only increase the salience of intergroup relations but also offer more opportunities for positive intergroup contact (Allport, 1954). As such, they might also provide more options to directly implement norms of tolerance and respect than culturally homogeneous school contexts (Verkuyten \& Thijs, 2013). However, despite its potential to reduce prejudice, emphasizing cultural differences may also increase the likelihood that young people will place individuals into rigid categories, thereby promoting stereotypes (Levy \& Hughes, 2009). Although, the empirical evidence of multicultural education's positive effects seems to outweigh potential negative consequences, scholars have called for more studies accounting for background characteristics, such as the level of cultural diversity at the national, regional, or school level to better understand its workings (Verkuyten \& Thijs, 2013).

\section{School and Classroom Climate and Youth's Intergroup Attitudes}

Schools bring together young people from various social and cultural backgrounds and according to the contact hypothesis (Allport, 1954), intergroup contact should reduce prejudice. Therefore, the level of cultural diversity in schools or classrooms has been regarded as a very prominent predictor of intergroup attitudes and relations (van Geel \& Vedder, 2011). Although findings on the direct effects of school or classroom diversity are not completely unambiguous, they point to beneficial outcomes (for a review, see Thijs \& Verkuyten, 2014). The effects of diversity depend, however, also on the prevailing conditions within the classroom or school context. Following Allport's contact hypothesis (Allport, 1954), a climate of support and cooperation among students (i.e., peer relationship climate) can challenge negative stereotypes, facilitate cross-ethnic friendship formation, and provide optimal conditions for positive intergroup contact, thereby amplifying its positive effects on intergroup attitudes (Tropp \& Prenovost, 2008). Yet, even in culturally homogeneous classroom or school contexts, a good peer relationship climate can contribute to more positive intergroup evaluations. According to social learning perspectives (e.g., Bandura, 1977), schools are microlevel societies and experiencing supportive relationships with peers can serve as a template for interactions with other people in and outside of school (Dessel, 2010). Research on the effects of a supportive peer relationship climate in school on intergroup attitudes is scarce and offers mixed results. While positive effects of cooperative relationships in class on attitudes toward immigrants were reported in a longitudinal study among Swedish youth (Miklikowska et al., 2021), no significant associations were found among a sample of German adolescents (Gniewosz \& Noack, 2008).

Apart from the peer relationship climate, another relevant - and related - characteristic of the school context is the prevailing democratic climate with student-teacher relations at its core. Attending a school where teachers encourage open discussion and provide opportunities to participate in decision making processes supports young people in becoming active and responsible citizens (Eckstein \& Noack, 2014). Again, in line with socialization and social learning perspectives (e.g., Bandura, 1977), schools allow for students to learn about social and political processes on a small scale and therefore a democratic climate has the 
potential to stimulate youth's own political awareness (Over $\&$ McCall, 2018). As part of a democratic climate, students may also experience that people, while differing in their opinions, beliefs, and lifestyles, can still treat each other with respect and openness. Tolerant attitudes toward diverse social groups can thus be another outcome of this process. The positive impact of a democratic classroom climate on adolescents' civic knowledge and engagement has been repeatedly demonstrated (Torney-Purta et al., 2001). There is also empirical evidence that a democratic classroom climate is associated with positive intergroup attitudes (e.g., Solhaug \& Osler, 2018). It should be noted, however, that democratic climate covers a broad spectrum of school experiences and, accordingly, has mostly been operationalized through various distinctive facets, such as open classroom climate for discussion (e.g., Carrasco \& Torres Irribarra, 2018), fairness of teachers (e.g., Miklikowska et al., 2019), or opportunities for participation in decision making processes (e.g., Higdon, 2015).

Taken together, apart from its ethnic composition, the school context offers a variety of factors potentially relevant to the development of adolescents' intergroup attitudes, such as school curriculum and school/classroom climate. While most research in this field is based on US and European samples, there are also large-scale assessments which allow for the consideration of school effects across various national contexts (e.g., International Civic and Citizenship Education Study, IEA ICCS; Schulz et al., 2018). Yet, studies employing longitudinal and multilevel designs are still rare.

\section{Age-Related Trends in the Effects of School Experiences}

Young people spend a very long period of time in school ranging from childhood to late adolescence. So far, however, the question of whether the effects of school experiences differ according to students' age remains largely unanswered. While experiences in school reach young people at a period in life that is generally considered to be of high relevance for the development of political attitudes and behaviors (Blakemore \& Mills, 2014), intergroup attitudes -particularly involving visible social categories such as cultural background or gender-were found to consolidate and stabilize early in life (see Barrett \& Oppenheimer, 2011 for a theoretical overview). Accordingly, attitudes toward immigrants were also shown to be well established already in early years and to increasingly stabilize throughout adolescence (Crocetti et al., 2021). Since once consolidated attitudes are less responsive to contextual influences, it may therefore be assumed that the effects of school experiences are less pronounced in older than in younger students (i.e., attitude consolidation hypothesis).
Alternatively, following the assumptions of motivational theories (e.g., Deci \& Ryan, 1985), adolescents' personal needs change over time. According to the stageenvironment fit theory (Eccles \& Midgley, 1989), the needs for autonomy, competence, and social relatedness increase throughout the adolescent years. In order to reach young people, schools should therefore account for these altering needs. Experiencing a school context that allows to engage in participatory-democratic principles (i.e., need for autonomy), to build strong relationships with peers (i.e., need for social relatedness), and to learn about cultural diversity (i.e., need for competence), might therefore be of higher relevance to older students than to younger students. As a consequence, it may also be assumed that older students are more susceptible to stimulating school experiences than younger students as they meet their altering needs (i.e., environment fit hypothesis). In addition, being exposed to characteristics of the school context for a longer period of time might also result in stronger effects of these factors in older students than in younger students. School experiences might then intensify over time. Applied to the area of crosscultural friendships, for example, it could be shown that time spent together is substantially associated with positive intergroup attitudes (Davies et al., 2011).

\section{Individual and Collective Perceptions of School Experiences}

Due to its multilevel nature, there are different perspectives on the school context. Although they might be biased, individual perceptions have been considered to be one crucial indicator. People react to their environment depending on how they perceive it, and therefore the significance of individual perceptions has been stressed in early sociological (Thomas \& Thomas, 1928) and later social cognition research (Bodenhausen \& Morales, 2012). However, individual perceptions may also vary systematically between students from different classrooms or schools. Students from the same school environment are exposed to the same routines, processes, and characteristics, which may contribute to certain dynamics and facilitate shared interpretations at the contextual level (Konishi et al., 2017). Disentangling individual level from classroom or school level effects can thus provide a more comprehensive understanding of schools' workings, as processes may operate differently at different levels (Marsh et al., 2012). This is also important from a methodological and practical point of view. Methodologically, one and the same construct might have specific psychometric properties and meanings depending on the level of analysis (Lüdtke et al., 2009). Finally, accounting for individual and contextual processes has practical significance, as with tight schedules 
and a high diversity of students' individual characteristics, it is difficult for teachers and educational staff to reach every single student in class. Thus, in order to provide guidelines for scalable interventions, it is important to gain a better understanding of processes operating not only at the individual but also at the classroom or school level.

\section{Background Information on the National and Regional Context}

In line with contextual models of human development (e.g., Bronfenbrenner, 1979), the development of intergroup attitudes cannot be completely understood independently from macrocontextual characteristics. While school or classroom diversity has been considered a prominent predictor of intergroup attitudes at the school or classroom level (Thijs \& Verkuyten, 2014), it also reflects processes at the broader societal level. Each country is characterized by a unique history of immigration. In Germany, this history varies considerably between regions and especially between the federal states in the Western and Eastern part (i.e., former German Democratic Republic, GDR) of the country. The present research is based on data that were collected in the federal state of Thuringia, historically a culturally rather homogenous region located in the Eastern part of Germany. Despite a steep increase of the immigrant population (i.e., people who immigrated to Germany themselves or have at least one parent who migrated to Germany) during the last decade (2010-2020), only around 7\% of the total population of Thuringia is of immigrant descent (compared to 27\% at the national level; Thüringer Ministerium für Migration, Justiz und Verbraucherschutz, TMMJV, 2019). The largest share of people of immigrant descent in Thuringia comes from Eastern European countries (e.g., Poland, Ukraine) and the former Soviet Union. Since 2015, refugees from crisis regions (e.g., Syria) represent an increasingly significant group (TMMJV, 2019). Although the proportion of people without an educational degree is higher among people of immigrant descent compared with people without immigrant background, educational inequalities between people with and without immigrant background were nonetheless found to be less pronounced in Thuringia than in other federal states of Germany (TMMJV, 2019).

Despite the low degree of cultural diversity within this region, national surveys repeatedly revealed substantial amounts of prejudice and intolerance toward immigrants (Reiser et al., 2018). This has, among others, been explained in terms of fewer opportunities for direct contact with people of varying cultural backgrounds (Pfister, 2018). Correspondingly, respondents from the Eastern part of Germany were found to have fewer cross-cultural friendships than respondents from the Western part (Zick et al.,
2019). In the absence of cultural diversity, yet prevalent negative sentiments toward immigrants, the school context may play a particularly important role for youth's attitudes as it can help students to reflect on privileges of the cultural majority and challenge prejudice (Swalwell, 2012).

\section{The Present Study}

Although the empirical literature on school effects on youth's attitudes toward immigrants is growing, to date there are still few longitudinal studies that also distinguished between individual- and contextual-level effects. Moreover, previous studies have rarely considered agerelated susceptibility to school experiences. Drawing on longitudinal multilevel data from Germany, the present study aimed to address these gaps in the literature. As part of the study's design, students who were either in 6th, 8th, or 10th grade at the first measurement point were surveyed over a period of 3 years. This allowed considering the effects of school experiences over a span of several years, ranging from 6th grade to 12 th grade, therewith covering almost the entire period of secondary education in Germany. Within the multilevel framework, classrooms were chosen as unit of analysis at the contextual level, since students spent most of their time in class and generally remained in the same class over time. Microlevel dynamics within class were therefore expected to significantly shape students' school experiences.

The first research question examined the effects of perceived multicultural education, supportive peer relationships in class, and democratic classroom climate on youth's negative attitudes toward immigrants across time at the individual level (Level 1) and at the classroom level (Level 2). In line with socialization and social learning perspectives (e.g., Bandura, 1977), all three school characteristics were expected to be associated with less negative attitudes toward immigrants. Due to conceptual considerations underscoring the role of individual perceptions as well as higher-level dynamics, associations were expected both at the individual and classroom level.

The second research question addressed age-specific trends in the effects of school experiences. Based on theoretical as well as empirical findings both stronger effects among younger students (attitude consolidation hypothesis) and older students (environment fit hypothesis) may be expected. Therefore, an explorative approach was chosen which did not further specify assumptions concerning the age-related pattern of effects. This also applied to the level of analysis and thus the question whether agespecific patterns may primarily affect individual or classroom level processes. 


\section{Method}

\section{Sample}

The present study was based on data from a comprehensive longitudinal project on adolescents' civic development in the federal state of Thuringia in Germany (Noack, 2005). The sample consisted of 1292 adolescents who were surveyed over a period of three measurement points, each approximately 1 year apart (2003-2005). Adolescents' age at the first measurement point (T1) was 13.86 years $(S D=$ 1.45, age range: $12-18$ years). Students came from different grade levels and were either in 6th $(n=394,30.5 \%)$, 8th $(n=435,33.6 \%)$, or 10 th grade $(n=463,35.9 \%)$ at T1 Students' average age in the youngest cohort (i.e., 6th grade $)$ was 12.29 years at $\mathrm{T} 1\left(M_{\mathrm{ageT} 2}=13.25, M_{\mathrm{ageT} 3}=\right.$ 14.37). Students' average age in the middle aged cohort (i.e., 8th grade) was 13.48 years at $\mathrm{T} 1 \quad\left(M_{\text {ageT2}}=14.50\right.$, $M_{\text {ageT3 }}=15.46$ ), and students' age in the oldest cohort (i.e., 10th grade $)$ was 15.52 at $\mathrm{T} 1\left(M_{\mathrm{ageT} 2}=16.41, M_{\mathrm{ageT} 3}=\right.$ $17.43)$. Gender was roughly equally distributed $\left(n_{\text {female }}=\right.$ $669,51.8 \%$ ). Only a few students reported not having German citizenship ( $n=16,1.2 \%)$. This low proportion is characteristic of this region in Germany (TMMJV, 2019). All participating schools were randomly selected from two major school tracks-a higher, college-bound track (Gymnasium) leading to the qualification exams to enter university (i.e., Abitur) after grade 12, and a lower, more practically oriented track (Regelschule) designed to lead to apprenticeship-based vocational training after grade 10 . Altogether, 73 classes from 36 higher and lower track schools were included in the study, whereby the number of participating schools was equally distributed across both school types. The number of students per class varied between 6 and $28(M=17.69, S D=5.79)$. Slightly more students attended the college-bound track $(n=760,58.8 \%)$ than the practically oriented track $(n=532,41.2 \%)$.

The procedure of data collection was similar for all schools: Once schools had agreed to participate, students and parents were asked for their consent. Finally, the survey was conducted during an extra-curricular lesson in class. Students completed a questionnaire on different civic topics, which took approximately $90 \mathrm{~min}$. During this time a research assistant from the project was present in class to administer the survey. After each measurement point, classrooms received a small contribution to the class fund.

\section{Measures}

If not indicated differently, the response options ranged from $1=\mathrm{I}$ do not agree at all to $4=\mathrm{I}$ totally agree. A complete summary of the scales' item wordings is provided in the online supplemental material (Supplementary Table S1).

\section{Negative attitudes toward immigrants}

Attitudes toward immigrants were assessed with six items (e.g., "Immigrants take away our jobs"; Balke et al., 2002; Dicke et al., 2000; Kracke \& Held, 1994). Cronbach's alpha coefficients indicated good internal consistencies $\left(\alpha_{\mathrm{T} 1}=\right.$ $0.83, \alpha_{\mathrm{T} 2}=0.86, \alpha_{\mathrm{T} 3}=0.86$ ).

\section{School Experiences}

School experiences were assessed by three indicators covering different facets of the school environment at Time 1. Perceived Multicultural Education was assessed with a single item ("Some teachers try very hard to familiarize us with the culture and points of view in other countries"). Supportive Peer Relations in class were assessed with four items (e.g., "There is a strong sense of community in our class"; $\alpha_{\mathrm{T} 1}=0.64$; Eder, 1998). Democratic Classroom Climate was measured by a 7-item-scale that included questions referring to open classroom climate for discussion, teachers' fairness, and participation in decisions (e.g., "Students are encouraged to make up their minds about issues"; Eder, 1998; Torney-Purta et al., 2001; $\alpha_{\mathrm{T} 1}=0.77$ ). Besides students' individual ratings, class-average ratings of all three school experiences were obtained by aggregating students' individual responses at the classroom level (see Analytical Procedure).

\section{Covariates}

Age (in years), Gender $(0=$ male, $1=$ female), SES (i.e., level of parental education; $1=$ no degree, $2=$ finishing school after 8 th grade, $3=$ finishing school after 10th grade, $4=$ Abitur/finishing school after 12 th grade, $5=$ university degree $)$, Citizenship $(0=$ non-German, $1=$ German $)$ and School Track $(0=$ lower track, $1=$ higher track $)$ served as covariates. Grade level (age cohort; i.e., 6th, 8th, 10th grade at T1) was furthermore considered as moderator variable.

\section{Attrition Analysis}

As in most longitudinal studies, not all students continued to participate in the survey throughout the years (complete data: $n=583,45.1 \%$ of initial sample). Overall, two patterns of missingness emerged: 458 students (35.4\%) were missing only at one wave, while $251(19.4 \%)$ were missing at two waves. Little's MCAR test (Little, 1988), which included all study variables, was significant $\left(\chi^{2}[318]=318.23, p<\right.$ 0.001 ) suggesting that data were not missing completely at random. To gain a deepened understanding, follow-up analyses were run in which adolescents with no missing data were compared to adolescents who did not participate at one or more measurement points $(n=709,54.9 \%)$. At Time 
1 students with and without missing data did not differ in their negative attitudes toward immigrants $(t[1290]=1.176$, $p=0.240)$. Likewise, analyses yielded no significant differences concerning gender $\left(\chi^{2}[1, N=1292]=1.377, p=\right.$ $0.214)$, SES $(t[1280]=1.334, p=0.180)$, or citizenship status $(t[1282]=0.378, p=0.706)$. Yet, lower track students had significantly more missing data than higher track students $\left(\chi^{2}[1, N=1292]=25.050, p<0.001\right)$ and older students had significantly more missing data than younger students $(t[1290]=15.381, p<0.001)$. These two patterns can be explained by the study's design. Since lower track students left school after 10th grade, they could no longer be reached in school for participation at the later measurement points, which caused a systematic drop-out among older and lower track students. In order to prevent a further reduction of the initial sample size, missingness was addressed using a full information maximum likelihood approach (maximum likelihood estimation with robust standard errors, MLR; see, e.g., Jeličič et al., 2009).

\section{Analytic Procedure}

To account for the hierarchical nature of the data with students being nested within classrooms (and schools), multilevel modeling was used. In doing so, classrooms were chosen as the unit of analysis at the contextual level. Students spent most of their time in classrooms and primary analyses showed that the proportion of variance at the classroom level was comparable-if not greater-than the amount of variance located at the school level ${ }^{1}$.

Two-Level Growth Curve Modeling with manifest indicators was employed using Mplus 8.6 (Muthèn \& Muthèn, 1998-2017) to examine changes in youth's negative attitudes toward immigrants at the individual level (Level 1) and classroom level (Level 2) across time (T1-T3). As part of the model specification, the intercept factor was defined as the initial status at Time 1 (i.e., latent mean at T1). The slope factor describes the amount of linear change in youth's negative attitudes toward immigrants from one measurement point to another.

In a first step, an unconditional model was specified to depict average trajectories in the entire sample (Model 1). In a second step, school experiences were added to the analyses at the individual and classroom level (Model 2.1-2.3), while also controlling for the effects of significant covariates (Model 3.1-3.3). The effects of school experiences on the intercept and slope factor were examined simultaneously at

\footnotetext{
${ }^{1}$ Intraclass correlations for negative attitudes toward immigrants at the school level were: $\mathrm{ICC}_{\mathrm{T} 1}=0.10$, ICC ${ }_{\mathrm{T} 2}=0.09$, and $\mathrm{ICC}_{\mathrm{T} 3}=$ 0.09 . Intraclass correlations for school experiences at $\mathrm{T} 1$ were as follows: ICC $=0.05$ for perceived multicultural education, $\mathrm{ICC}=0.07$ for supportive peer relations in class, and $\mathrm{ICC}=0.07$ for democratic classroom climate.
}

the individual and at the classroom level. In order to do so, individual ratings were aggregated at the classroom level whereby the resulting mean is considered as indicator of collective perceptions at Level 2 (Lüdtke et al., 2009). Since Mplus offers a latent aggregation of Level 1 predictors, the aggregated Level 2 indicators are treated as latent variables (i.e., multilevel latent covariate model; Lüdtke et al., 2008). This approach has shown to correct for unreliability of Level 2 indicators and to lead to less biased parameter estimates (Lüdtke et al., 2009). In the case of significant Level 1 and Level 2 effects, it was further assessed whether the relationship found at the classroom level was significantly different from the relationship at the individual level (i.e., contextual effect; difference between Level 1 and Level 2 effect; Raudenbush \& Bryk, 2002). For models including covariates (Model 3.1-3.3), Level 1 covariates (i.e., age, gender, SES, citizenship) were centered at their grand mean, since this centering option allows for accounting for covariate effects at Level 1 and Level 2 (Lüdtke et al., 2009).

In a third step, it was examined whether the effects of school experiences on negative attitudes toward immigrants would differ according to students' age. Since in multilevel modeling, higher-level variables are usually conceptualized as moderator (e.g., Aguinis et al., 2013) and since students of the same age group attended the same grade level (6th, 8th, 10th grade at $\mathrm{T} 1)^{2}$, the latter was chosen as moderator variable. This allowed taking the data's age-based grouping further into account. Due to its categorical scaling, grade level was dummy coded, whereby the youngest age group (6th grade at T1) served as reference category. Two sets of moderation analyses were carried out: (1) To test whether grade level (Level 2 variable) would moderate the association between individual perceptions of school experiences and negative attitudes toward immigrants (Level 1 relationship), cross-level interactions were specified (via random-slope multilevel modeling; Model 4.1-4.3). (2) To test for interactions between classaverage perceptions of school experiences and grade level, interaction terms between each school variable and the dummy coded grade level indicators were created and added as predictors at Level 2 (Model 5.1-5.3).

Maximum likelihood estimation with robust standard errors (MLR) was used for all analyses, since it has been shown to be robust against deviations from statistical assumptions (Field \& Wilcox, 2017). Finally, model fit was evaluated based on established fit indices ( $\mathrm{Hu} \&$ Bentler, 1999 $)^{3}$. Unless indicated differently, the estimated models fit the data well.

\footnotetext{
${ }^{2}$ The correlation between age and grade level was $r_{\mathrm{sp}}=0.92$.

3 The following fit indices were considered: Chi-square $\left(\chi^{2}\right)$ associated with degrees of freedom $(d f)$ and $p$ value as well as CFI (comparative fit index), TLI (Tucker-Lewis index), RMSEA (root mean square error of approximation), and SRMR (standardized root mean square residual).
} 
Table 1 Zero-order correlations and intraclass correlations of main study variables

\begin{tabular}{|c|c|c|c|c|c|c|c|c|c|}
\hline \multicolumn{2}{|c|}{ Variables } & \multirow{2}{*}{$\frac{M}{2.51}$} & \multirow{2}{*}{$\frac{S D}{0.74}$} & \multirow{2}{*}{$\frac{1}{0.15 / 0.76}$} & \multirow{2}{*}{$\frac{2}{0.77^{* *}}$} & \multirow{2}{*}{$\frac{3}{0.60 * *}$} & \multirow{2}{*}{$\frac{4}{-0.18}$} & \multirow{2}{*}{$\frac{5}{-0.29^{*}}$} & \multirow{2}{*}{$\frac{6}{0.03}$} \\
\hline 1 & Anti-Immigrant Attitudes T1 & & & & & & & & \\
\hline 2 & Anti-Immigrant Attitudes T2 & 2.55 & 0.75 & $0.63 * *$ & $0.12 / 0.70$ & $0.67 * *$ & -0.13 & 0.21 & 0.02 \\
\hline 3 & Anti-Immigrant Attitudes T3 & 2.52 & 0.72 & $0.55 * *$ & $0.67 * *$ & $0.10 / 0.67$ & -0.19 & -0.25 & 0.12 \\
\hline 4 & Dem. Classroom Climate & 2.88 & 0.46 & -0.02 & $-0.06^{*}$ & $-0.11 * *$ & $0.12 / 0.70$ & $0.79 * *$ & $0.53 * *$ \\
\hline 5 & Supportive Relations in Class & 2.87 & 0.55 & $-0.06^{*}$ & $-0.06^{*}$ & $-0.09 *$ & $0.40 * *$ & $0.15 / 0.75$ & 0.35 \\
\hline 6 & Multicultural Education & 2.73 & 0.75 & 0.02 & 0.02 & 0.04 & $0.36 * *$ & $0.21 * *$ & $0.05 / 0.48$ \\
\hline
\end{tabular}

Correlations at the individual level (Level 1) are displayed below the diagonal, correlations at the classroom level (Level 2) are displayed above the diagonal, ICC(1)/ICC(2) are presented in italic font within the diagonals. $N_{\mathrm{L} 1}=1292$ students, $N_{\mathrm{L} 2}=73$ classrooms with average size of 17.69 students/class

$* p<0.05, * * p<0.01$

\section{Results}

\section{Preliminary Analyses}

\section{Zero-order correlations}

Table 1 summarizes zero-order correlations at Level 1 and Level 2 for the main study variables. At the individual level, supportive peer relations in class and democratic classroom climate (at T2 and T3) were negatively related with attitudes toward immigrants. At the classroom level, only supportive peer relations in class showed a significant association with negative attitudes toward immigrants at $\mathrm{T} 1$.

\section{Psychometric quality of classroom-level constructs}

To determine whether the aggregation of individual ratings resulted in reliable indicators of higher-level processes, intraclass correlation coefficients (ICC) were estimated. While ICC(1) describes the amount of variation between classrooms, ICC(2) assesses the reliability of class-level means (as indicator of the "true" classroom mean; Lüdtke et al., 2009). The results are summarized in Table 1. Except for perceived multicultural education, ICC(1)s were larger than 0.10 , indicating that more than $10 \%$ of the variance for negative attitudes toward immigrants, supportive peer relations in class, and democratic classroom climate was located at the classroom level, supporting the adoption of a multilevel perspective to the research questions (Julian, 2001). Estimations of ICC(2) for negative attitudes toward immigrants were 0.76 at $\mathrm{T} 1,0.70$ at $\mathrm{T} 2$, and 0.67 at T3 and, thus, above or close to the recommended cut-off value of 0.70 (Bliese, 1998). While values of ICC(2) were also adequate for supportive peer relationships (0.76) and democratic classroom climate (0.70), the value was considerably lower for perceived multicultural education (0.48).

\section{Main Analyses}

\section{Effects of school experiences on negative attitudes toward immigrants}

At first, a baseline model was specified to depict average changes in youth's negative attitudes toward immigrants (Model $1 ; \chi^{2}[1, N=1192]=0.68, p=0.411, \mathrm{CFI}=1.000$, $\mathrm{TLI}=1.000, \quad \mathrm{RMSEA}=0.000, \quad \mathrm{SRMR}_{\mathrm{Within}}=0.000$, $\mathrm{SRMR}_{\text {Between }}=0.007$ ). The results showed no significant mean-level changes across time, as indicated by the nonsignificant slope mean $(B=0.003, S E=0.015, p=0.830)$. Yet, at the individual level, both the intercept $\left(\sigma^{2}=0.316\right.$, $S E=0.033, p<0.001)$ and the slope variance $\left(\sigma^{2}=0.053\right.$, $S E=0.014, p<0.001)$ were significantly different from zero pointing to interindividual differences at $\mathrm{T} 1$ and in changes across time. While there was also significant variation around the intercept factor at the classroom level $\left(\sigma^{2}=0.078, S E=0.019, p<0.001\right)$, no significant variation was found around the slope factor $\left(\sigma^{2}=0.003, S E=0.008\right.$, $p=0.669)$, indicating that there were no significant differences between classrooms in their rate of change. Due to this lack of variation, the slope variance was constrained to zero, which did not significantly affect model fit $\left[\Delta \chi^{2}(2)=\right.$ $2.15, p=0.341]^{4}$. Effects on the slope factor at the classroom level were therefore not further considered in subsequent analyses 5 .

Next, school experiences were added to the analyses to predict the intercept and slope factor at the individual and classroom level. In doing so, each school indicator was considered separately for its predictive value (Models 2.1-2.3;

\footnotetext{
${ }^{4}$ To account for the MLR estimation of the present analyses, this difference test was conducted using the log-likelihood values and MLR scaling correction factors. The test statistic of this difference test is also chi-square distributed.

${ }^{5}$ In follow-up analyses, it was tested whether there were any effects of school experiences on the slope factor at the classroom level which, however, were all far from significance.
} 
Table 2 Prediction of negative attitudes toward immigrants by school experiences

\begin{tabular}{|c|c|c|c|c|c|c|c|c|c|c|c|c|}
\hline \multirow[b]{4}{*}{ Level 1} & \multicolumn{4}{|c|}{$\begin{array}{l}\text { Perceived multicultural education } \\
\text { as predictor of attitudes }\end{array}$} & \multicolumn{4}{|c|}{$\begin{array}{l}\text { Supportive peer relationships } \\
\text { as predictor of attitudes }\end{array}$} & \multicolumn{4}{|c|}{$\begin{array}{l}\text { Democratic classroom climate } \\
\text { as predictor of attitudes }\end{array}$} \\
\hline & \multicolumn{4}{|l|}{ Model 2.1} & \multicolumn{4}{|c|}{ Model 2.2} & \multicolumn{4}{|c|}{ Model 2.3} \\
\hline & Intercept & & Slope & & Intercept & & Slope & & Intercept & & Slope & \\
\hline & $B$ & $S E$ & $B$ & $S E$ & $B$ & $S E$ & $B$ & $S E$ & $B$ & $S E$ & $B$ & $S E$ \\
\hline School experience & 0.02 & 0.03 & 0.01 & 0.02 & -0.02 & 0.05 & -0.01 & 0.03 & -0.00 & 0.05 & $-0.06 *$ & 0.03 \\
\hline$R^{2}$ & 0.00 & 0.00 & 0.00 & 0.00 & 0.00 & 0.00 & 0.00 & 0.00 & 0.00 & 0.00 & 0.02 & 0.01 \\
\hline \multicolumn{13}{|l|}{ Level 2} \\
\hline School experience & -0.05 & 0.27 & - & - & $-0.48^{* *}$ & 0.17 & - & - & $-0.43^{*}$ & 0.21 & - & - \\
\hline \multirow[t]{3}{*}{$R^{2}$} & 0.00 & 0.00 & - & - & 0.16 & 0.11 & - & - & 0.07 & 0.07 & - & - \\
\hline & \multicolumn{4}{|l|}{ Model 3.1} & \multicolumn{4}{|c|}{ Model 3.2} & \multicolumn{4}{|c|}{ Model 3.3} \\
\hline & Intercept & & Slope & & Intercept & & Slope & & Intercept & & Slope & \\
\hline Level 1 & $B$ & $S E$ & $B$ & $S E$ & $B$ & $S E$ & $B$ & $S E$ & $B$ & $S E$ & $B$ & $S E$ \\
\hline School experience & 0.01 & 0.03 & 0.01 & 0.02 & -0.03 & 0.05 & -0.01 & 0.02 & -0.02 & 0.04 & $-0.06^{*}$ & 0.03 \\
\hline Age & -0.03 & 0.02 & - & - & -0.03 & 0.02 & - & - & -0.03 & 0.02 & - & - \\
\hline Gender & $-0.09 *$ & 0.04 & - & - & -0.09 & 0.05 & - & - & $-0.09^{*}$ & 0.04 & - & - \\
\hline SES & $-0.07 * *$ & 0.03 & - & - & $-0.07 * *$ & 0.03 & - & - & $-0.07 * *$ & 0.03 & - & - \\
\hline Citizenship & $0.77 * *$ & 0.08 & - & - & $0.81^{* *}$ & 0.09 & - & - & $0.81 * *$ & 0.08 & - & - \\
\hline$R^{2}$ & $0.05 * *$ & 0.02 & 0.00 & 0.00 & $0.05^{* *}$ & 0.01 & 0.00 & 0.00 & $0.05^{* *}$ & 0.01 & 0.02 & 0.01 \\
\hline \multicolumn{13}{|l|}{ Level 2} \\
\hline School experience & $-0.84 * *$ & 0.31 & - & - & $-0.37 *$ & 0.16 & - & - & $-0.56^{* *}$ & 0.32 & - & - \\
\hline School track & $-0.40^{* *}$ & 0.06 & - & - & $-0.29 * *$ & 0.06 & - & - & $-0.32 * *$ & 0.05 & - & - \\
\hline$R^{2}$ & $0.83 * *$ & 0.17 & - & - & $0.63 * *$ & 0.11 & - & - & $0.68^{* *}$ & 0.10 & - & - \\
\hline
\end{tabular}

$B$ unstandardized parameter estimate, $S E$ standard error

Level $1=$ individual level, Level $2=$ classroom level. $N_{\mathrm{L} 1}=1292$ students, $N_{\mathrm{L} 2}=73$ classrooms

${ }^{*} p<0.05, * * p<0.01$

for fit indices, see Supplementary Table S2). Table 2 provides a summary of the findings. No significant effects on the intercept or slope factor were found for perceived multicultural education-neither at the individual nor at the classroom level. While supportive peer relations in class also showed no significant effect on the intercept or slope factor at the individual level, there was a significant effect on the intercept factor at the classroom level $(\beta=-0.405, S E=0.133, p=0.002)$. This effect was significantly stronger than the Level 1 effect (contextual effect: $B=-0.461, S E=0.174, p=0.008)$, indicating that irrespective of whether students personally perceived relations to peers in class to be supportive, they reported fewer negative attitudes if they were in classrooms which were on average characterized by high levels of supportive peer relations (see Table 2). And finally, while the results at the individual level for democratic classroom climate also revealed no significant effect on the intercept factor, there was a significant effect on the slope factor $(\beta=-0.119$, $S E=0.050, p=0.017)$, indicating that youth who perceived the classroom climate as more democratic at $\mathrm{T} 1$ reported a decline in negative attitudes toward immigrants across time compared to youth who perceived the classroom climate to be less democratic. Moreover, as was the case for supportive peer relations in class, there was a significant effect on the intercept factor at the classroom level $(\beta=-0.271, S E=0.135, p=0.045)$. Again, this effect was significantly different from the effect at the individual level (contextual effect: $B=0.426, S E=0.210, p=0.043$ ). Thus, irrespective of whether students personally perceived their classrooms to be democratic, they reported fewer negative attitudes toward immigrants if they came from classrooms in which students perceived the average climate to be democratic.

In a next step, the models were repeated while also controlling for significant covariate effects ${ }^{6}$ (i.e., age, gender, citizenship, and SES on the intercept at Level 1 and school track on the intercept at Level 2; Models 3.1-3.3; for fit indices, see Supplementary Table S2). The findings are also summarized in Table 2. Whereas the results at the individual level remained the same after controlling for covariate effects, the result pattern changed at the classroom level. In addition to supportive peer relations in class and democratic classroom climate, perceived multicultural education also showed a significant effect on the intercept factor at Level $2(\beta=-0.572$, $S E=0.193, p=0.003$, see Table 2 for unstandardized

\footnotetext{
${ }^{6}$ The covariates age, gender, SES, citizenship status (Level 1) and school track (Level 2) showed only significant effects on the intercept factor. Since there were no significant covariate effects on the slope factor, these effects were constrained to zero in the model estimation.
} 
Table 3 Moderation analyses examining effects of school experiences at Level 1 on negative attitudes toward immigrants according to age group (grade level)

\begin{tabular}{|c|c|c|c|c|c|c|c|c|c|c|c|c|}
\hline \multirow[b]{4}{*}{ Level 1} & \multicolumn{4}{|c|}{$\begin{array}{l}\text { Perceived multicultural } \\
\text { education as predictor of } \\
\text { attitudes }\end{array}$} & \multicolumn{4}{|c|}{$\begin{array}{l}\text { Supportive peer relationships as } \\
\text { predictor of attitudes }\end{array}$} & \multicolumn{4}{|c|}{$\begin{array}{l}\text { Democratic classroom climate as } \\
\text { predictor of attitudes }\end{array}$} \\
\hline & \multicolumn{4}{|c|}{ Model 4.1} & \multicolumn{4}{|c|}{ Model 4.2} & \multicolumn{4}{|c|}{ Model 4.3} \\
\hline & \multicolumn{2}{|l|}{ Intercept } & \multicolumn{2}{|l|}{ Slope } & \multicolumn{2}{|l|}{ Intercept } & \multicolumn{2}{|l|}{ Slope } & \multicolumn{2}{|l|}{ Intercept } & \multicolumn{2}{|l|}{ Slope } \\
\hline & $B$ & $S E$ & $B$ & $S E$ & $B$ & $S E$ & $B$ & $S E$ & $B$ & $S E$ & $B$ & $S E$ \\
\hline School experience & 0.04 & 0.06 & -0.03 & 0.03 & 0.00 & 0.08 & -0.01 & 0.04 & -0.06 & 0.08 & $-0.09 *$ & 0.04 \\
\hline \multicolumn{13}{|l|}{ Level 2} \\
\hline Constant & 2.41 & 0.42 & - & - & 3.72 & 0.38 & - & - & 3.39 & 0.48 & - & - \\
\hline School experience & -0.04 & 0.14 & - & - & $-0.40 * *$ & 0.12 & - & - & -0.29 & 0.16 & - & - \\
\hline Dummy_Grade 8 & 0.10 & 0.08 & - & - & 0.04 & 0.08 & - & - & 0.05 & 0.09 & - & - \\
\hline Dummy_Grade 10 & -0.07 & 0.09 & - & - & -0.13 & 0.07 & - & - & -0.12 & 0.08 & - & - \\
\hline \multicolumn{13}{|l|}{ Cross-level Interaction } \\
\hline School experience $\times$ Dummy_Grade 8 & -0.04 & 0.07 & 0.06 & 0.04 & -0.10 & 0.10 & 0.03 & 0.06 & -0.13 & 0.11 & 0.07 & 0.06 \\
\hline School experience $\times$ Dummy_Grade 10 & -0.02 & 0.08 & 0.06 & 0.04 & 0.01 & 0.12 & 0.02 & 0.06 & -0.06 & 0.13 & 0.07 & 0.06 \\
\hline \multicolumn{13}{|l|}{ Additional Information } \\
\hline$\sigma^{2}$ Level 1 & $0.32 * *$ & 0.03 & $0.06^{* *}$ & 0.01 & $0.31 * *$ & 0.03 & $0.05 * *$ & 0.01 & $0.31 * *$ & 0.03 & $0.05 * *$ & 0.01 \\
\hline$\sigma^{2}$ Level 2 & $0.06 * *$ & 0.01 & - & - & $0.05 * *$ & 0.01 & - & - & $0.06^{* *}$ & 0.01 & - & - \\
\hline AIC & \multicolumn{4}{|l|}{5357.792} & \multicolumn{4}{|l|}{5520.540} & \multicolumn{4}{|l|}{5520.191} \\
\hline $\mathrm{BIC}$ & \multicolumn{4}{|l|}{5485.884} & \multicolumn{4}{|l|}{5649.393} & \multicolumn{4}{|l|}{5649.134} \\
\hline
\end{tabular}

$B$ unstandardized parameter estimate, $S E$ standard error, AIC Akaike information criterion, BIC Bayesian information criterion

Level $1=$ individual level, Level $2=$ classroom level. Dummy_Grade $8(0=$ other, $1=$ grade 8$)$, Dummy_Grade $10(0=$ other, $1=$ grade 10$)$

$* p<0.05, * * p<0.01$

parameter estimates). Accordingly, when taking age, gender, citizenship, SES, and school track differences into account, students from classrooms in which teachers were perceived to explicitly address cultural issues reported fewer negative attitudes toward immigrants than students from classrooms in which cultural topics were not explicitly addressed. A follow-up analysis showed that the significant association between multicultural education and negative attitudes toward immigrants at the classroom level was only present among male students from higher track schools. ${ }^{7}$

\footnotetext{
7 To see whether the changed pattern concerning the effect of perceived multicultural education on the intercept factor at Level 2 might be driven by a particular covariate besides age, follow-up analyses were conducted. Among the Level 1 covariates only gender showed to significantly interact with the Level 2 effect of perceived multicultural education $(B=0.785, \quad S E=0.329, p=0.017)$. However, when accounting for school track at Level 2, the results pointed to a further interplay between school track and gender. More precisely, the results revealed a three-way interaction between gender, school track, and perceived multicultural education at Level $2(B=0.720, S E=0.295$, $p=0.015)$. Accordingly, as shown in Supplementary Table S3, the significant association between perceived multicultural education and negative attitudes toward immigrants at Level 2 was only apparent among male students from higher track schools.
}

\section{Grade level as moderator of the effects of school experiences}

In a last step, it was examined whether the effects of school experiences on negative attitudes toward immigrants differed according to age (i.e., grade level). To do so, a further set of two-level growth curve models was conducted, which included the cross-level interactions examining whether the effect of students' individual perceptions of school experiences on the intercept or slope factor at Level 1 different according to grade level (i.e., dummy coded Level 2 indicator, Model 4.1-4.3). As in all previous model specifications, the classroom level effects of school experiences on the intercept at Level 2 were also taken into account. The results showed that neither the effects of perceived multicultural education, nor supportive peer relations in class, or democratic classroom climate at Level 1, differed according to grade level. Table 3 summarizes the main model coefficients.

Subsequently, age-specific patterns were tested for all classroom level effects (Model 5.1-5.3). As part of the model specification, the intercept factor at Level 2 was predicted by school experience, grade level indicators (dummy coded), and the interaction terms between school experience and grade level. The effects of school experiences were also included at Level 1 (on the intercept and slope factor). The results showed 
Table 4 Moderation analyses examining effects of school experiences at Level 2 on negative attitudes toward immigrants according to age group (grade level)

\begin{tabular}{|c|c|c|c|c|c|c|c|c|c|c|c|c|}
\hline \multirow[b]{4}{*}{ Level 1} & \multicolumn{4}{|c|}{$\begin{array}{l}\text { Perceived multicultural education } \\
\text { as predictor of attitudes }\end{array}$} & \multicolumn{4}{|c|}{$\begin{array}{l}\text { Supportive peer relationships as } \\
\text { predictor of attitudes }\end{array}$} & \multicolumn{4}{|c|}{$\begin{array}{l}\text { Democratic classroom climate as } \\
\text { predictor of attitudes }\end{array}$} \\
\hline & \multicolumn{4}{|c|}{ Model 5.1} & \multicolumn{4}{|c|}{ Model 5.2} & \multicolumn{4}{|c|}{ Model 5.3} \\
\hline & \multicolumn{2}{|c|}{ Intercept } & \multicolumn{2}{|l|}{ Slope } & \multicolumn{2}{|c|}{ Intercept } & \multicolumn{2}{|l|}{ Slope } & \multicolumn{2}{|l|}{ Intercept } & \multicolumn{2}{|l|}{ Slope } \\
\hline & $B$ & $S E$ & $B$ & $S E$ & $B$ & $S E$ & $B$ & $S E$ & $B$ & $S E$ & $B$ & $S E$ \\
\hline School experience & 0.02 & 0.03 & 0.01 & 0.02 & -0.03 & 0.05 & -0.01 & 0.03 & -0.00 & 0.05 & $-0.06^{*}$ & 0.03 \\
\hline \multicolumn{13}{|l|}{ Level 2} \\
\hline Constant & 2.27 & 0.51 & - & - & 2.73 & 0.75 & - & - & 2.37 & 0.79 & - & - \\
\hline School experience & 0.09 & 0.18 & - & - & -0.14 & 0.24 & - & - & 0.06 & 0.25 & - & - \\
\hline Dummy_Grade 8 & -0.04 & 0.85 & - & - & 0.26 & 1.01 & - & - & 0.14 & 1.05 & - & - \\
\hline Dummy_Grade 10 & 1.00 & 0.87 & - & - & 1.37 & 0.92 & - & - & 2.85 & 0.97 & - & - \\
\hline $\begin{array}{l}\text { School experience } \times \\
\text { Dummy_Grade } 8\end{array}$ & 0.06 & 0.30 & - & - & -0.07 & 0.34 & - & - & -0.01 & 0.36 & - & - \\
\hline $\begin{array}{l}\text { School experience } \times \\
\text { Dummy_Grade } 10\end{array}$ & -0.40 & 0.32 & - & - & -0.51 & 0.30 & - & - & $-1.01 * *$ & 0.32 & - & - \\
\hline
\end{tabular}

$B$ unstandardized parameter estimate, $S E$ standard error

Level $1=$ individual level, Level $2=$ classroom level. Dummy_Grade $8(0=$ other, $1=$ grade 8$)$, Dummy_Grade $10(0=$ other, $1=$ grade 10$)$ $* p<0.05, * * p<0.01$

that class-average perceptions of perceived multicultural education and supportive peer relationships did not vary by grade level. Yet, grade level moderated the Level 2 effect of democratic classroom climate (see Table 4). A follow-up analysis in which the effects were considered separately according to grade level showed that class-average perceptions of a democratic classroom climate were significantly associated with fewer negative attitudes toward immigrants at $\mathrm{T} 1$ among 10th grade students $(\beta=-0.682, S E=0.210, p=0.001)$, while the effects were not significant among students from 6 th and 8 th grade (grade 6: $\beta=0.062, S E=0.151, p=0.682$; grade $8: \beta=$ $0.060, S E=0.270, p=0.823)$. The interaction is also displayed in Fig. 1. It should be noted that a similar tendency emerged for supportive peer relationships in class, although the interactions with the dummy coded grade level indicators did not reach significance (associations between supportive peer relationships at Level 2 and negative attitudes toward immigrants according to grade level; grade $6: \beta=-0.175, S E=$ $0.180, p=0.331$; grade 8: $\beta=-0.194, S E=0.266, p=0.466$; grade 10: $\beta=-0.626, S E=0.286, p=0.028$ ). The associations between perceived multicultural education at Level 2 and negative attitudes toward immigrants were not significant for all grade levels (grade 6: $\beta=0.114, S E=0.146, p=0.436$; grade $8: \quad \beta=0.165, S E=0.347, \quad p=0.633$; grade 10 : $\beta=-0.134, S E=0.271, p=0.621$ ).

\section{Sensitivity analyses}

Excluding classrooms with less than 10 students $\left(n_{\text {classrooms }}=\right.$ $7, n_{\text {students }}=56$ ) or adding grade level as an additional covariate at Level 2 (in Model 3.1-3.3) did not affect the overall pattern of findings. The results were also replicated when all school experiences were examined simultaneously in one model. The only exceptions were the Level 2 effects of democratic classroom climate and supportive peer relations in class. Both variables were highly correlated at the classroom level $(r=0.79$, see Table 1$)$ and therefore confounded. After accounting for this, however, the overall pattern of results could be replicated.

\section{Discussion}

With its goal to educate tolerant and mature citizens, schools have been described as an important socialization context in youth (Neundorf \& Smets, 2017). While school experiences were shown to be related to youth's intergroup attitudes (e.g., Barber et al., 2013), the empirical evidence for that is still limited, especially with respect to longitudinal designs. Moreover, although school experiences accompany young people from late childhood into late adolescence, age-specific effects have rarely been considered to date. The present 3-wave study from Germany aimed to contribute to the literature by accounting for the effects of perceived multicultural education, supportive peer relations in class, and democratic classroom climate on German youth's negative attitudes toward immigrants. Due to the data's multilevel and cohort-sequential nature, processes at the individual and classroom level could be compared over a wide age span ranging from 12 to 18 years. Although the results revealed few effects at the individual level (i.e., only for democratic classroom climate), all three 
Fig. 1 Association between democratic classroom climate at Level 2 and attitudes toward immigrants at according to age group (grade level)

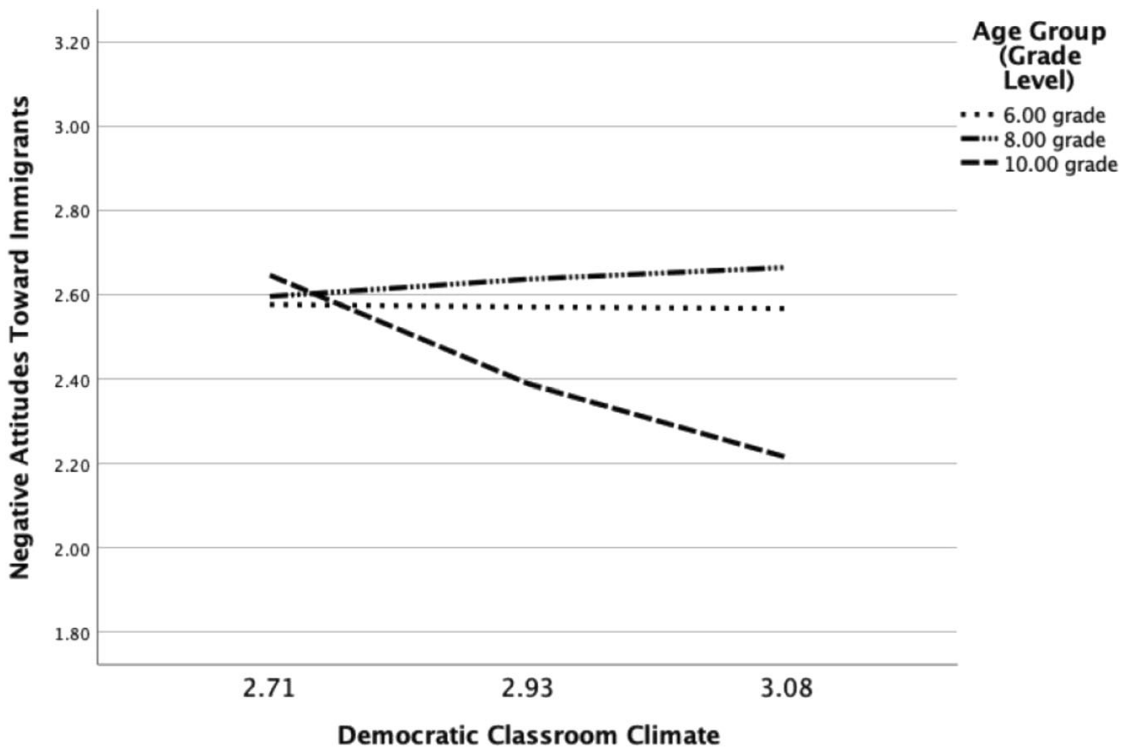

school indicators were cross-sectionally related to less negative attitudes toward immigrants at the classroom level (for perceived multicultural education, however, only after controlling for the effects of socio-demographic covariates). Moreover, age-related patterns were found for the effect of democratic climate at the classroom level, pointing to stronger effects among older than among younger students.

\section{School Experiences and Attitudes toward Immigrants}

The results for the first research question can be summarized in three patterns: First, perceived multicultural education was not related to youth's negative attitudes toward immigrants at the individual level (neither cross-sectionally at Time 1 nor longitudinally across time). This is not in line with previous research showing significant effects of multicultural education on intergroup attitudes (e.g., Verkuyten \& Thijs, 2013) and might be related to the characteristics of the sample. Data were collected in a region of Germany where only around $7 \%$ of the population are of immigrant descent (TMMJV, 2019) and, consequently, the students in the current study experienced culturally homogeneous school environments. Therefore, questions about cultural diversity that usually arise from everyday interactions between class- or schoolmates may either not have developed at all or might have been personally less salient than in culturally heterogeneous school contexts. Consequently, individual perceptions of teachers' handling of cultural topics might also be less relevant for youth's intergroup attitudes. Indeed, research has shown that multicultural education is more frequently applied in culturally diverse than in homogeneous classrooms (Thijs \& Verkuyten, 2014).
However, at the classroom level, the bivariate association between class-average perceptions of multicultural education and youth's attitudes toward immigrants was significant for male students from higher track classrooms (see Footnote 7 and Supplementary Table S3). One possible explanation for the responsiveness of this particular subgroup might be that at the contextual level, higher track classrooms are characterized by a less negative climate toward immigrants than lower track classrooms (e.g., Schmid \& Watermann, 2010), which could facilitate the discussion of cultural-related topics. In addition - and in line with previous research (Higdon, 2015)-male students reported more negative attitudes toward immigrants than female students. Like intergroup contact, multicultural education might be particularly beneficial for more prejudiced youth (e.g., Hodson \& Dhont, 2015). Hence, while more prejudiced male students might be more responsive to classroom-level effects of multicultural education, it may require the additional impact of a non-prejudiced classroom environment for multicultural education to unfold its effects. To draw firm conclusions, however, a more nuanced investigation of the interplay between socio-demographic variables and dynamics within the classroom is needed.

Second, no significant effects emerged for supportive peer relations in class at the individual level (neither crosssectionally nor longitudinally). The absence of a Level 1effect might be attributed to the fact that the indicator explicitly addressed dynamics within class. Research showed more consistent associations at the individual level by using a measure that focused on personal feelings of social belonging in school (Gniewosz \& Noack, 2008). Future studies could therefore compare the effects of individual- vs. classroom-oriented indicators of peer relations more systematically. However, there was a significant effect 
of supportive peer relations at the classroom level at Time 1. Thus, irrespective of how students personally perceived their relationships with classmates, there were certain dynamics at the classroom level that mattered. Theoretically, the classroom-level effect is in line with social learning and socialization perspectives (Bandura, 1977). Being surrounded by supportive peers seems to set an example of how to relate to other people inside or outside of school (Dessel, 2010). While this finding is consistent with previous research showing associations between cooperative peer relations and youth's attitudes toward immigrants (Miklikowska et al., 2021), it further adds to these studies by showing that supportive relations with classmates do matter in culturally homogeneous school settings where opportunities for cross-cultural contact are limited.

Third, while students' individual perception of a democratic classroom climate had no significant effect at Time 1, it predicted a decline in negative attitudes toward immigrants across time at the individual level. At the classroom level, class-average perceptions of a democratic classroom climate were also associated with less negative attitudes toward immigrants at Time 1 . These results are generally consistent with previous studies using more narrow and specific indicators of democratic classroom climate (i.e., perceived teacher support and fairness (Miklikowska et al., 2019), open classroom climate for discussion (Carrasco \& Torres Irribarra, 2018), or participation in decision making processes (Higdon, 2015). This study therefore replicates the effects found in existing literature with a broader indicator of democratic classroom climate. Together with previous research, and also in line with social learning and socialization perspectives (Bandura, 1977), these results suggest that experiencing a climate in which people can differ in their opinions and lifestyles, but still treat each other with respect contributes to the development of less prejudiced intergroup attitudes. However, the results also revealed different patterns at the individual and classroom level. Whereas a longitudinal effect was found at the individual level, the dynamics at the classroom level are reflected in a cross-sectional association (yet only among older students). The longitudinal effect at the individual level might be due to the fact that processes related to youth's individual perception need time to unfold. Thus, perceiving a democratic climate may encourage adolescents to reflect on their own political positions and to compare them to the views and lifestyles of others. While this may eventually shape youth's attitudes toward diverse groups, such school experiences are often not a matter of conscious decision. Therefore, students may need to personally experience a democratic school climate for some time for its effects to take hold. To better understand the underlying processes, future studies should compare potential mediating variables at the individual and at the classroom level in order to gain insight into the respective mechanism.
In sum, school experiences were found to be related to youth's negative attitudes toward immigrants. At the same time, the findings underscore that both processes at the individual and contextual level should be considered, supporting the adoption of a multilevel perspective. The most consistent effects of school experiences were identified at the classroom level, which is important from a pedagogical and practical perspective. Tight curricula and a high diversity of students' individual needs make it difficult for teachers to reach every single student in class. Therefore, a deepened understanding of processes operating at the classroom level could help to provide more general recommendations or guidelines for teachers. Although addressing unfavorable intergroup attitudes within school is a long and challenging task, it is the knowledge about underlying processes that provides a crucial starting point. Raising teachers' and students' awareness of the importance of social and democratic processes in class could be a first step. The integration of collaborative learning strategies, interactive and engaging classroom activities, or instructional methods that promote a dialog between teachers and students might then represent some practical and concrete examples of how to foster an open and supportive climate.

\section{Age-related Trends in the Effects of School Experiences}

The second research question examined whether the effects of school experiences on youth's negative attitudes toward immigrants would differ according to students' age (i.e., grade level). While no indication of age-specific effects of school experiences at the individual level was found, the results showed that the dynamics at the classroom level differed by grade level. In particular, class-average perceptions of democratic classroom climate were only associated with less negative attitudes toward immigrants among older (10th grade) but not younger students (6th or 8th grade). This result is in line with the assumptions of the stage-environment fit theory (Eccles \& Midgley, 1989). It suggests that a democratic classroom context may meet students' growing needs for autonomy and efficacy. It might, however, also mean that a longer exposure to a democratic classroom dynamic is needed to observe its effects. Future studies should therefore examine the processes underlying age-specific patterns in greater detail.

Although there was also a tendency for the effect of supportive peer relations at the classroom level to be stronger among older than among younger students, the moderation by grade level did not reach significance. The attenuated age-related pattern might be explained by the fact that peer relations are-despite changes in structure and dynamics - of high significance throughout the 
adolescent years (Bowker \& Ramsey, 2011). There was also no indication that the effect of perceived multicultural education on students' negative attitudes toward immigrants differed by grade level. These results are not in line with the environment fit hypothesis. Students seem to have the necessary cognitive capacity to benefit from the existence of multicultural educational strategies at the outset of adolescence. Correspondingly, a meta-analytical overview found the effects of multicultural education on intergroup attitudes to be stronger among adolescent than among pre-adolescent students, but did not assume the effects to differ within the adolescent group (Okoye-Johnson, 2011).

In sum, age-related trends were identified for the classroom-level effect of democratic climate, which was only related to attitudes toward immigrants among older but not among younger students. This indicates that age matters, yet only for certain school indicators. Further research on age-related effects of school experiences is needed to draw more definite conclusions about the generalizability of these findings. Knowing about specific processes depending on students' or schools' contextual characteristics can help to provide more tailored advice for schools to create an inclusive environment and to develop strategies to reduce prejudice.

\section{Limitations and Future Research}

Some limitations of this research need to be noted. As in most longitudinal studies, not all students participated at all measurement points. Attrition was particularly high among older and lower track students. To account for the potential impact of data attrition, missing values were taken into account in the model estimation. Although this is a highly recommended method to deal with missingness (Jeličič et al., 2009), a possible bias due to data attrition cannot be completely ruled out. Conceptually, it should be noted that school experiences were examined while drawing on indicators primarily reflecting classroom level processes (i.e., supportive peer relations in class, democratic classroom climate). Since the students in the present study spent most of their time within classrooms, these microlevel dynamics represent an important aspect of their school-based experiences. Yet, to get a more holistic understanding of contextual processes, future studies should further differentiate dynamics at the classroom and school level.

Several limitations concern the adopted measures. First, while the internal consistency of supportive peer relationships at Level 2 was adequate, it was only marginally acceptable at the individual level. To account for measurement error, latent measurement models could, for example, be specified at the individual level in future studies. Second, the measure of perceived multicultural education, which was based on a single-item indicator, poses another limitation (e.g., Loo, 2002). Reliability estimates of class-average ratings [i.e., ICC(2)] furthermore remained clearly below the recommended threshold. Besides these psychometric limitations, conceptually broader indicators should be applied in future studies. Apart from addressing cultural topics, educational strategies that foster students' critical thinking or discuss discrimination and racism could be included as well (for an overview see Verkuyten \& Thijs, 2013). Third, negative attitudes toward immigrants were assessed with an explicit measure and might therefore underlie a certain bias due to students' external or internal motivation to respond without prejudice (Plant \& Devine, 1998). Although similar indicators were used in previous studies (e.g., Miklikowska et al., 2021), more research comparing explicit and implicit measures of intergroup attitudes among adolescents is needed to gain a thorough understanding of processes causing and maintaining negative attitudes toward immigrants (see, for example, Ewoldsen, 2020).

Finally, several characteristics of the data set need to be pointed out: The study was conducted in the federal state of Thuringia in Germany, which is culturally a rather homogenous region (with currently approx. $7 \%$ of the population being of immigrant descent). Although this shows that school experiences matter for adolescents' intergroup attitudes even in the absence of cultural diversity, research from other regions is needed to test for the generalizability of these findings. Another limitation relates to the year of data collection, which dates back to 2003-2005. Although the considered region in Germany is still characterized by low levels of cultural diversity, immigration has increased in recent years. While a general trend toward more tolerant attitudes toward diversity could be observed over the past decades, political polarization rose at the same time (Follmer et al., 2018). Voices critical of immigration, for example, became distinctively louder in the aftermath of swiftly increased numbers of refugees across Europe in 2015 and, concurrently, right-wing populist parties experienced a significant rise in support (Steinmayr, 2021). To better understand such macrocontextual processes, it would be interesting for future studies to account for the potential workings of societal processes, such as the salience of migration-related issues, and its impact on youth's attitudes toward immigrants.

\section{Conclusion}

Just as societies become increasingly diverse, strategies aimed at fostering positive intergroup attitudes are needed. This also applies to regions characterized by low levels of cultural diversity and thus limited opportunities for cross- 
cultural contact. Adolescence is a sensitive period for the development of intergroup attitudes. This development is shaped by experiences in proximal socialization contexts, such as schools. The findings of the present study show that school experiences, such as a democratic classroom climate or supportive relations to classmates, can help reduce the risk of prejudice development. At the same time, they also point at the necessity of accounting for the multilevel nature of the school context and individual student characteristics, such as age. By providing opportunities to learn about social interaction and democratic processes these findings emphasize, once again, that schools matter in youth's sociopolitical development.

Authors' Contributions K. E. conceived of the study, participated in its design, conducted the analyses, and drafted the manuscript; M. M. conceived of the study, drafted parts of the manuscript, and participated in the interpretation of the data; P.N. participated in the design of the study, coordination of the data collection, and interpretation of the data. All authors read, edited, and approved the final manuscript.

Funding Open Access funding enabled and organized by Projekt DEAL. This research was supported by the German Research Foundation (DFG, FOR 481, No 213/9-4) by financial aid given to the third author and by the grants from Swedish Research Council (dnr 201604165) and Riksbankens Jubileumsfond (P20-0599) awarded to the second author.

Data Sharing and Declaration The datasets generated and/or analyzed during the current study are not publicly available but are available from the corresponding author on reasonable request.

\section{Compliance with Ethical Standards}

Conflict of Interest The authors declare no competing interests.

Ethical Approval The research this study based on was approved by the Ethics Committee of the Faculty of Social and Behavioural Sciences at Friedrich Schiller University Jena, Germany and the Thuringian Ministry of Education.

Informed Consent Informed consent was obtained from all individual participants included in the study.

Publisher's note Springer Nature remains neutral with regard to jurisdictional claims in published maps and institutional affiliations.

Open Access This article is licensed under a Creative Commons Attribution 4.0 International License, which permits use, sharing, adaptation, distribution and reproduction in any medium or format, as long as you give appropriate credit to the original author(s) and the source, provide a link to the Creative Commons license, and indicate if changes were made. The images or other third party material in this article are included in the article's Creative Commons license, unless indicated otherwise in a credit line to the material. If material is not included in the article's Creative Commons license and your intended use is not permitted by statutory regulation or exceeds the permitted use, you will need to obtain permission directly from the copyright holder. To view a copy of this license, visit http://creativecommons. org/licenses/by/4.0/.

\section{References}

Aboud, F. E., \& Levy, S. R. (2000). Interventions to reduce prejudice and discrimination in children and adolescents. In S. Oskamp (Ed.), Reducing prejudice and discrimination (pp. 269-293). Lawrence Erlbaum Associates Publishers

Allport, G. W. (1954). The nature of prejudice. Addison-Wesley

Aguinis, H., Gottfredson, R. K., \& Culpepper, S. A. (2013). Bestpractice recommendations for estimating cross-level interaction effects using multilevel modeling. Journal of Management, 39(6), 1490-1528. https://doi.org/10.1177/0149206313478188

APA, American Psychological Association (n.d.). Attitude. APA dictionary of psychology. Retrieved August 30, 2021, from https:// dictionary.apa.org/attitude

Balke, D., El-Menouar, Y., \& Rastetter, R. U. (2002). Einschätzung von Kosten durch Zuwanderer [Estimation of costs due to immigrants]. In A. Glöckner-Rist (Ed.), ZUMA-Informationssystem. Elektronisches Handbuch sozialwissenschaftlicher Erhebungsinstrumente. ZIS Version 6. Zentrum für Umfragen, Methoden und Analysen, Mannheim, Germany

Bandura, A. (1977). Self-efficacy: Toward a unifying theory of behavioral change. Psychological Review, 84(2), 191-215. https://doi.org/10.1016/0146-6402(78)90002

Banks, J. A., \& Banks, C. A. M. (2004). Handbook of research on multicultural education (2nd ed.). Jossey-Bass

Barber, C., Fennelly, K., \& Torney-Purta, J. (2013). Nationalism and support for immigrants' rights among adolescents in 25 countries. Applied Developmental Science, 17(2), 60-75. https://doi.org/10. 1080/10888691.2013.774870

Barrett, M., \& Oppenheimer, L. (2011). Findings, theories and methods in the study of children's national identifications and national attitudes. European Journal of Developmental Psychology, 8(1), 5-24. https://doi.org/10.1080/17405629.2010.533955

Blakemore, S. J., \& Mills, K. L. (2014). Is adolescence a sensitive period for sociocultural processing? Annual Review of Psychology, 65(1), 187-207. https://doi.org/10.1146/annurev-psych-010213-115202

Bliese, P. D. (1998). Group size, ICC values, and group-level correlations: A simulation. Organizational Research Methods, 1(4), 355-373. https://doi.org/10.1177/109442819814001

Bodenhausen, G. V., \& Morales, J. R. (2012). Social cognition and perception. In H. Tennen, J. Suls, \& I. B. Weiner (Eds.), Handbook of psychology: Personality and social psychology (pp. 225-246). John Wiley \& Sons, Inc

Bowker A., \& Ramsay K. (2011). Friendship characteristics. In R. Levesque (Ed.), Encyclopedia of adolescence. Springer. https:// doi.org/10.1007/978-3-319-32132-5_49-2

Bronfenbrenner, U. (1979). The ecology of human development: Experiments by nature and design. Harvard University Press

Carrasco D., \& Torres Irribarra D. (2018). The role of classroom discussion. In A. Sandoval-Hernández A., \& M. M. Isac. (Eds.), Teaching tolerance in a globalized world. IEA research for education: A series of in-depth analyses based on data of the International Association for the Evaluation of Educational Achievement (IEA). Springer. https://doi.org/10.1007/978-3-319-78692-6_6

Crocetti, E., Albarello, F., Prati, F., \& Rubini, M. (2021). Development of prejudice against immigrants and ethnic minorities in adolescence: A systematic review with meta-analysis of longitudinal studies. Developmental Review, 60. https://doi.org/10. 1016/j.dr.2021.100959

Davies, K. R., Tropp, L. R., Aron, A., Pettigrew, T. F., \& Wright, S. C. (2011). Cross-group friendships and intergroup attitudes: A metaanalytic review. Personality and Social Psychology Review, 15 (4), 332-351. https://doi.org/10.1177/1088868311411103

Deci, E. L., \& Ryan, R. M. (1985). Intrinsic motivation and selfdetermination in human behavior. Plenum 
Dessel, A. (2010). Prejudice in schools: Promotion of an inclusive culture and climate. Education and Urban Society, 42(4), 407-429. https://doi.org/10.1177/0013124510361852

Dicke, K., Edinger, M., \& Schmitt, K. (2000). Politische Kultur im Freistaat Thüringen: Ergebnisse des Thüringen-Monitors 2000 [Political culture in the state of Thuringia: Results of the Thuringia monitor 2000]. Drucksache des Thüringer Landtags $3 / 1106$

Eccles, J. S., \& Midgley, C. (1989). Stage-environment fit: Developmentally appropriate classrooms for young adolescents. In R. Ames, \& C. Ames (Eds.), Research on motivation and education: Goals and cognitions (pp. 139-186). Academic Press

Eccles, J. S., \& Roeser, R. W. (2009). Schools, academic motivation, and stage-environment fit. In R. M. Lerner \& L. Steinberg (Eds.), Handbook of adolescent psychology: Individual bases of adolescent development (pp. 404-434). John Wiley \& Sons Inc. https://doi.org/10.1002/9780470479193.adlpsy001013

Eckstein, K., \& Noack, P. (2014). Students' democratic experiences in school: A multilevel analysis of social-emotional influences. International Journal of Developmental Science, 8(3-4), 105-114. https://doi.org/10.3233/DEV-14136

Eder, F. (1998). Linzer Fragebogen zum Schul- und Klassenklima für die 8.-13. Klasse (LFSK 8-13) [Linzer questionnaire of schooland classroom climate for grades 8 to 13]. Hogrefe

Ewoldsen, D. R. (2020). Implicit and explicit measures of prejudice. In J. Bulck (Ed.). The international encyclopedia of media psychology. Wiley. https://doi.org/10.1002/9781119011071.iemp0078

Field, A. P., \& Wilcox, R. R. (2017). Robust statistical methods: A primer for clinical psychology and experimental psychopathology researchers. Behaviour Research and Therapy, 98, 19-38. https:// doi.org/10.1016/j.brat.2017.05.013

Follmer, R., Kellerhoff, J., \& Wolf, F. (2018). Vom Unbehagen an der Vielfalt. [On the discomfort of diversity]. BertelsmannStiftung. https://www.bertelsmann-stiftung.de/de/publikationen/publika tion/did/vom-unbehagen-an-der-vielfalt

Gniewosz, B., \& Noack, P. (2008). Classroom climate indicators and attitudes towards foreigners. Journal of Adolescence, 31(5), 609-624. https://doi.org/10.1016/j.adolescence.2007.10.006

Hess, D. E. (2009). Controversy in the classroom: The democratic power of discussion. Routledge.

Higdon, J. D. (2015). Measuring and modeling intercultural attitudes among adolescents across Europe: A multi-level, multiple-group analysis examining student attitudes, intergroup contact, and school climate. [Unpublished doctoral dissertation]. Harvard Graduate School of Education

Hodson, G., \& Dhont, K. (2015). The person-based nature of prejudice: Individual difference predictors of intergroup negativity. European Review of Social Psychology, 26(1), 1-42. https://doi. org/10.1080/10463283.2015.1070018

Hu, L., \& Bentler, P. M. (1999). Cutoff criteria for fit indexes in covariance structure analysis: Conventional criteria versus new alternatives. Structural Equation Modeling, 6(1), 1-55. https:// doi.org/10.1080/10705519909540118

Jeličič, H., Phelps, E., \& Lerner, R. M. (2009). Use of missing data methods in longitudinal studies: The persistence of bad practices in developmental psychology. Developmental Psychology, 45(4), 1195-1199. https://doi.org/10.1037/a0015665

Julian, M. W. (2001). The consequences of ignoring multilevel data structures in nonhierarchical covariance modeling. Structural Equation Modeling, 8(3), 325-352. https://doi.org/10.1207/ S15328007SEM0803_1

Konishi, C., Miyazaki, Y., Hymel, S., \& Waterhouse, T. (2017). Investigating associations between school climate and bullying in secondary schools: Multilevel contextual effects modeling. School Psychology International, 38(3), 240-263. https://doi.org/ $10.1177 / 0143034316688730$
Kracke, B., \& Held, M. (1994). Dokumentation der Erhebungsinstrumente des Projekts "Individuation und sozialer Wandel" [Documentation of the survey instruments of the project "Individuation and social change"]. University of Mannheim, Germany

Levy, S. R., \& Hughes, J. M. (2009). Development of racial and ethnic prejudice among children. In T. D. Nelson (Ed.), Handbook of prejudice, stereotyping, and discrimination (pp. 23-42). Psychology Press

Little, R. J. A. (1988). A test of missing completely at random for multivariate data with missing values. Journal of the American Statistical Association, 83(404), 1198-1202. https://doi.org/10. 2307/2290157

Loo, R. (2002). A caveat on using single-item versus multiple-item scales. Journal of Managerial Psychology, 17(1), 68-75. https:// doi.org/10.1108/02683940210415933

Lüdtke, O., Marsh, H. W., Robitzsch, A., Trautwein, U., Asparouhov, T., \& Muthén, B. (2008). The multilevel latent covariate model: A new, more reliable approach to group-level effects in contextual studies. Psychological Methods, 13(3), 203-229. https:// doi.org/10.1037/a0012869

Lüdtke, O., Robitzsch, A., Trautewin, U., \& Kunter, M. (2009). Assessing the impact of learning environments: How to use student ratings of classroom and school characteristics in multilevel modeling. Contemporary Educational Psychology, 34(2), 120-131. https://doi.org/10.1016/j.cedpsych.2008.12.001

Marsh, H. W., Lüdtke, O., Nagengast, B., Trautwein, U., Morin, A. J. S., Abduljabbar, A. S., \& Köller, O. (2012). Classroom climate and contextual effects: Conceptual and methodological issues in the evaluation of group-level effects. Educational Psychologist, 47(2), 106-124. https://doi.org/10.1080/00461520.2012.670488.

Miklikowska, M., Eckstein, K., \& Matera, J. (2021). All together now: Cooperative classroom climate and the development of youth attitudes toward immigrants. New Directions for Child and Adolescent Development. Advance online publication. https://doi. org/10.1002/cad.20414

Miklikowska, M., Thijs, J., \& Hjerm, M. (2019). The impact of perceived teacher support on anti-immigrant attitudes from early to late adolescence. Journal of Youth and Adolescence, 48(6), 1175-1189. https://doi.org/10.1007/s10964-019-00990-8

Muthén, L. K., \& Muthén, B. O. (1998-2017). Mplus user's guide: Eighth edition. Muthén \& Muthén. https://www.statmodel.com/ download/usersguide/MplusUserGuideVer_8.pdf

Neundorf, A., \& Smets, K. (2017). Political socialization and the making of citizens. In Oxford Handbooks Online. Oxford University Press. https://doi.org/10.1093/oxfordhb/9780199935307.013.98

Noack, P. (2005). Schulbasierte Einflüsse auf die politisch-soziale (In-) Toleranz Jugendlicher [School-based effects on the political and social (in-)tolerance of juveniles]. Unpublished DFG Research Report FOR 481/2, Friedrich-Schiller-University Jena, Germany

Okoye-Johnson, O. (2011). Does multicultural education improve students' racial attitudes? Implications for closing the achievement gap. Journal of Black Studies, 42(8), 1252-1274. https:// doi.org/10.1177/0021934711408901

Over, H., \& McCall, C. (2018). Becoming us and them: Social learning and intergroup bias. Social and Personal Psychology Compass, 12(4), 1-13. https://doi.org/10.1111/spc3.12384

Plant, E. A., \& Devine, P. G. (1998). Internal and external motivation to respond without prejudice. Journal of Personality and Social Psychology, 75(3), 811-832. https://doi.org/10.1037/00223514.75.3.811

Pfister, G. (2018). Fremdenfeindlichkeit in Deutschland? Einstellungen gegenüber Ausländern 2016 [Xenophobia in Germany? Attitudes Toward Foreigners 2016]. [Doctoral dissertation] Julius-Maximilians-Universität Würzburg, Germany. https://opus.bibliothek. uni-wuerzburg.de/opus4-wuerzburg/frontdoor/deliver/index/ docId/16807/file/Pfister_Gerd_Dissertation.pdf 
Raudenbush, S. W., \& Bryk, A. S. (2002). Hierarchical linear models. Sage Publications

Reiser, M., Best, H., Salheiser, A., \& Vogel, L. (2018). Heimat Thüringen. Ergebnisse des Thüringen Monitors 2018 [Home Thuringia. Results of the Thuringia Monitor 2018]. Retrieved August 31, 2021, from https://www.landesregierung-thueringen. de/regierung/th-monitor

Scheerens, J. (2011). Indicators on informal learning for active citizenship at school. Educational Assessment, Evaluation and Accountability, 23(3), 201-222. https://doi.org/10.1007/s11092-011-9120-8

Schmid, C., \& Watermann, R. (2010). Schulische Prozessmerkmale und ausländerfeindliche Einstellungen bei Jugendlichen[Schoolbased process indicators and the development of youths" xenophobic attitudes]. Zeitschrift für Soziologie der Erziehungund Sozialisation, 30(1), 74-95.

Schulz, W., Ainley, J., Fraillon, J., Losito, B., Agrusti, G., \& Friedman, T. (2018). Becoming citizens in a changing world. SpringerOpen. https://doi.org/10.1007/978-3-319-73963-2

Sears, D. O., \& Levy, S. (2003). Childhood and adult political development. In D. O. Sears, L. Huddy, \& R. Jervis (Eds.), Oxford handbook of political psychology (pp. 60-109). Oxford University Press

Solhaug, T., \& Osler, A. (2018). Intercultural empathy among Norwegian students: An inclusive citizenship perspective. International Journal of Inclusive Education, 22(1), 89-110. https://doi. org/10.1080/13603116.2017.1357768

Steinmayr, A. (2021). Contact versus exposure: Refugee presence and voting for the far right. The Review of Economics and Statistics, 103(2), 310-327. https://doi.org/10.1162/rest_a_00922

Swalwell, K. (2012). Confronting white privilege. Teaching Tolerance, 42, 23-26

Thijs, J., \& Verkuyten, M. (2014). School ethnic diversity and students' interethnic relations. British Journal of Educational Psychology, 84(1), 1-21. https://doi.org/10.1111/bjep.12032

Thomas, W. I., \& Thomas, D. S. (1928). The child in America: Behavior problems and programs. Alfred A. Knopf

Thüringer Ministerium für Migration, Justiz und Verbraucherschutz (TMMJV, 2019). Thüringer Zuwanderungs- und Integrationsbericht 2019 [Thuringian Immigration and Integration Report 2019]. Retrieved August 31, 2021, from https://bimf. thueringen.de/integration/zib

Torney-Purta, J., Lehmann, R., Oswald, H., \& Schulz, W. (2001). Citizenship and education in twenty-eight countries: Civic knowledge at age fourteen. IEA.

Tropp, L. R., \& Prenovost, M. (2008). The role of intergroup contact in predicting interethnic attitudes: Evidence from meta-analytic and field studies. In S. Levy, \& M. Killen (Eds.), Intergroup attitudes and relations in childhood through adulthood (pp. 236-248). Oxford University Press

van Bommel, G., Thijs, J., \& Miklikowska, M. (2020). Parallel empathy and group attitudes in late childhood: The role of perceived peer group attitudes. The Journal of Social Psychology, 161(3), 337-350. https://doi.org/10.1080/00224545.2020.1840326

van Geel, M., \& Vedder, P. (2011). Multicultural attitudes among adolescents: The role of ethnic diversity in the classroom. Group Processes \& Intergroup Relations, 14(4), 549-558. https://doi. org/10.1177/1368430210379007

Verkuyten, M., \& Thijs, J. (2013). Multicultural education and interethnic attitudes: An intergroup perspective. European Psychologist, 18(3), 179-190. https://doi.org/10.1027/1016-9040/a000152

Zick A., Küpper B., \& Berghan W. (2019). Verlorene Mitte Feindselige Zustände. Rechtsextreme Einstellungen in Deutschland 2018/19 [Lost center - hostile states. Right-wing extremist attitudes in Germany 2018/19]. J. H. W. Dietz-Verlag.

Katharina Eckstein is a postdoctoral researcher at the Department of Educational Psychology at Friedrich Schiller University Jena, Germany. Her research interests include the development of civic attitudes and behaviors during adolescence/young adulthood, the role of family and school contextual influences in youth's civic development, as well as structural equation modeling and multilevel analysis techniques.

Marta Miklikowska is an Associate Professor (Docent) in sociodevelopmental psychology at Umeå University, Sweden. Her research focuses on anti-immigrant attitudes, empathy, cross-ethnic friendships, political activism as well as the role of social contexts (family, friends and school) in adolescent development.

Peter Noack is a Professor for Educational Psychology at Friedrich Schiller University Jena, Germany. His research interests include youth research, development and socialization in family and friendship relations, attitudes, learning behavior, and school achievement of students, as well as civic socialization. 